\title{
ADMINISTRAÇÃO NO BRASIL: POTENCIALIDADES, PROBLEMAS E PERSPECTIVAS
}

\author{
Domingos Giroletti \\ FCHL
}

"Tudo o que já foi, é o começo do que vai vir." Guimarães Rosa

0 título desta pensata traduz duas questões, igualmente instigantes e desafiadoras. A primeira permite uma reflexão sobre o crescimento e possível crise da Administração; e a segunda, os limites teóricos e empíricos da Administração para o século XXI. Nessa perspectiva, o desenvolvimento da pensata procura "passear" entre as duas questões a partir do reconhecimento inicial da positividade da profissional ização e institucionalização da Administração no Brasil. Na seqüência, são apresentados os problemas pertinentes à área e colocadas de forma conclusiva algumas reflexões relacionadas com seu desenvolvimento futuro.

Como ponto de partida, é imperativo admitir que a Administração institucionalizou-se e profissionalizouse no Brasil. Foi um processo longo, iniciado com a criação de disciplinas de Administração ensinadas em vários cursos superiores. Prosseguiu com a criação dos primeiros cursos de Economia e Administração. Consolidou-se com a sua autonomização como curso de graduação e, finalmente, com os diversos cursos de pós-graduação implantados no Brasil a partir da década de 1970.
Isso trouxe al guns aspectos positivos que merecem destaque. 0 primeiro é a evidência de que foi possível atender às demandas por gestores no Brasil provindas do setor público, das empresas privadas e, mais recentemente, do terceiro setor. Peter Drucker, em uma recente entrevista, reconhece a existência de uma "administração de qualidade internacional nas empresas brasileiras". Na mesma entrevista, observou que o país conseguiu desenvolver grupos de liderança executiva que permitiram criar empresas nacionais. Mesmo assim, é importante observar que talvez a falta mais aguda de bons administradores esteja no setor público, notadamente devido ao crescente e asfixiante achatamento salarial ao longo dos últimos anos, à falta de carreira compensadora e à pouca valorização profissional do servidor público admitido mediante concurso, preterido pela contratação de pessoas por meio de critérios político-partidários. Isso tem afastado os mel hores talentos da administração estatal. Há evidências de que o recrutamento amplo de servidores dificulta a adoção de práticas racionalizadoras e profissionais no espaço público.

O segundo aspecto positivo está relacionado à consolidação da pósgraduação, tendo como importantes elementos associados a expansão do ensino superior em Administração e a melhoria na formação do professor. A grande expansão do ensino superior em Administração pode ser visualizada pelos dados do Censo da Educação Superior do INEP/ MEC de 2003, em que a Administração aparece como o curso com 0 maior número de alunos: 564.681 alunos ou $14,5 \%$ do total. Por conseguinte, deve-se reconhecer que essa expansão é fruto do aumento do número e da qualidade dos professores. Somem-se a isso o crescente prestígio social da profissão e as mudanças processadas no mercado e no mundo do trabalho, com o estímulo crescente ao empreendedorismo e ações de natureza individual.

0 terceiro aspecto refere-se ao crescimento da pesquisa e à produção acadêmicas tanto em quantidade quanto em qualidade. A despeito da atração que o mercado e certas profissões de Estado exercem sobre os profissionais da Administração - oferecendo-Ihes melhores oportunidades de emprego, remuneração e renda, e outras vantagens - , não há dúvida de que uma parte significativa permaneceu na universidade, dedicando-se às atividades de ensino, pesquisa e extensão. A exigência de titulação e produção científica como condições de ingresso, permanência e progressão na carreira universitária são outros fatores a estimular a pesquisa e a qual ificação de novos mestres e doutores na área. 
Além desses aspectos, deve-se ainda mencionar a criação da Capes, do $\mathrm{CNPq}$ e de fundações estaduais de amparo à pesquisa, que passaram a disponibilizar recursos, assim como outros fatores de impacto positivo. A profissionalização e institucionalização da Administração podem ainda ser medidas por outros indicadores, tais como o número crescente de publicações em formatos impresso e el etrônico, a diversificação no formato do ensino em Administração, com a criação inclusive dos mestrados profissional izantes, e o saudável crescimento de trabalhos inscritos para congressos e encontros da Anpad, do Eneo, do 3Es e outras associações científicas do gênero.

Em que pesem os avanços e positividades mencionadas, há problemas que se referem ao ensino, à pesquisa e à produção científica da administração. 0 primeiro deles está relacionado à fal ta de uma história abrangente, profunda e atual do desenvolvimento da Administração no Brasil. Persiste uma lacuna, com ausência de uma história do desenvolvimento da área em amplitude e profundidade. Conhecer, e bem, o caminho percorrido é condição para refazê-lo, para definir novos trajetos e novos rumos. I mpõe-se um balanço histórico, profundo e abrangente: pensar e avaliar o que se fez, como se fez e se faz, para que se fez e para que e como se fará. Escrever essa História da Administração é uma necessidade e um desafio. Esse desafio natural mente não cabe a um único indivíduo, mas sim a um grupo interdisciplinar de pesquisa formado por pesquisadores de todo 0 país para levantar a produção regional, cobrindo a diversidade e multiplicidade dos programas, pesquisas e trabal hos.

O segundo problema está relacionado à transformação da expansão quantitativa do ensino superior de Administração em expansão qualitativa. Esse é um dos grandes desafios da área e de todo o ensino superior no Brasil. Pela atual legislação, a transformação da quantidade em qualidade estaria mais a cargo de mecanismos próprios do mercado, que se encarregariam de separar o joio do trigo, garantindo, ao final, a sobrevivência dos mel hores cursos. Mas isso não é suficiente. A natureza da educação, bem público e direito individual e social, não pode ser reduzida a uma commodity. É um serviço que requer regulamentação, fiscal ização e aval iação efetiva do Estado.

0 terceiro problema está relacionado à hiperespecialização do ensino de Administração. Além do crescimento desordenado e frouxidão na regulamentação pelo Estado, os novos cursos de Administração, para diferenciar-se um dos outros e no intuito de atrair maior clientela, têm adotado como estratégia a excessiva especialização. Essa opção vai a contrapel o da reforma universitária que se faz em outros países e da proposta de educação feita pela U nesco para o século XXI. Para a U nesco, e pelo projeto de reforma de universidade da União Européia, deveria predominar no ensino superior a formação teórica e generalista, postergando, ao máximo, a especialização. Aplicando-se a orientação da Unesco à Administração, pode-se afirmar que uma boa formação geral nesta área englobaria, com variações, meia dúzia de especial idades, quais sejam: gestão da produção (as novas bases produtivas, tecnológicas, e o uso generalizado da informática) e de recursos humanos, marketing, finanças, administração pública e do terceiro setor.

Ao contrário, o que se observa é que a estratégia adotada pelas no- vas faculdades de Administração é a oferta de cursos cal cados na especialização crescente como diferencial de mercado. Essa orientação se opõe não apenas à tendência mundial em educação, mas aos imperativos da gl obalização, com as transformações que ela impõe, e à demanda do mercado interno brasileiro, que não é tão diferenciado ou sofisticado para absorver todas essas especialidades. Pelo contrário, 0 mercado parece ser crescente para as profissões híbridas de caráter interdisciplinar. Na vida prática, a pessoa com formação geral se adapta mel hor do que o especial ista às situações de mudanças no emprego e no trabal ho provocadas pelas transformações tecnológicas constantes e em ritmo cada vez mais acelerado.

Um quarto problema está relacionado à ênfase excessiva no caráter prático do conhecimento. Com efeito, a marca da universidade desde sua fundação é promover a pesquisa e a didática em alto nível, mesmo com o acréscimo de novas competências de formar novos tal entos para as diferentes profissões e para 0 desenvolvimento cultural, social e econômico dos respectivos países onde atua. 0 ensino teórico, 0 desenvolvimento do raciocínio, a capacidade de abstração e general ização, a criatividade, a inovação, 0 empreendedorismo, o senso crítico e a capacidade analítica devem ter precedência sobre a prática. Esse espírito do pensamento científico, que se desdobra, deve impregnar o ensino e a formação dos al unos porque, se eles aprendem a se desdobrar como o pensamento científico faz com os seus achados, o novo profissional da Administração estará apto a acompanhar as mudanças do mundo globalizado, do mercado e das profissões, todos em transformação contínua e permanente. N es- 
sa perspectiva, abandonar o caráter crítico do conhecimento científico, filosófico ou artístico é um erro estratégico grave que muitas universidades estão cometendo.

Um quinto problema, decorrente em grande medida do aspecto anterior, está relacionado à idéia de a universidade "clonar" a empresa privada. Ouve-se, com freqüência, que 0 curso modelar de Administração é aquele que prepara o aluno para o mercado ou aquele que oferece um conhecimento prático ou simula a atmosfera futura da empresa onde irá trabalhar. Como as universidades podem oferecer isso se o mercado e o conhecimento prático de hoje não serão aqueles de amanhã? Não há como negar que o mercado e as empresas modificam-se com extrema velocidade. Por isso, dificilmente o que se ensina hoje na universidade valerá amanhã, ao final do curso, quando 0 aluno ingressar no mercado de trabalho.

Por esse fato, parece ser inútil a universidade querer "clonar" o mercado ou fazer o que as empresas sabem fazer melhor: ensinar rotinas, técnicas ou outros procedimentos operacionais ou administrativos. 0 que a universidade deverá fazer então? Como afirma Renato Janine Ribeiro, ela deverá proporcionar,

uma formação de uma base sólida o bastante para que, em meio às mudanças, o aluno saiba navegar. Devemos preparar os alunos para uma vida de tempestades. E uma das melhores bússolas é o conhecimento dos clássicos - não porque dêem lições imortais, invariáveis [...], mas porque, na sua diversidade, permitem exercitar o espírito com tal liberdade diante das injunções do cotidiano que, mudando este, a mente saiba encontrar um novo nicho, embora tão provisório quanto 0 anterior. (RIBEIRO, R. J. A universidade e a vida atual. Rio de Janeiro: Campus, 2003, p. 114).

Além de não se confundir, não pode rivalizar com a empresa privada, ao pretender anteci par-se às mudanças rápidas e intermitentes do mercado. A universidade é uma instituição que não pode ser confundida com 0 mercado, mas também não pode desconhecê-lo. 0 mercado será sempre um dos seus interlocutores.

Um sexto problema está relacionado aos "efeitos colaterais" do crescimento da administração, e referese à controvérsia sobre a qualidade da produção. Sobre essa discussão, parece importante mencionar 0 artigo de Silvia Roesch "Quem responde pelo desempenho limitado da produção científica em administração no Brasil?" (O\& S, v. 10, n. 28, p. 165-7, 2003), em que esta autora levanta quatro fatores que merecem reflexão: o primeiro, técnico, é a "falta de rigor metodológico", que precisa ser corrigido. Os outros três são de ordem cultural: 0 "comodismo" - pelo mimetismo ou por posições conquistadas na carreira ou nos órgãos técnicos de pesquisa ou agências de fomento; a "impaciência" - por resultados intelectuais imediatos; e o "individualismo" pela exacerbação da competição, entre nós, de programas e instituições. A reprodução desses traços negativos permite, em grande medida, a observância de sua manifestação na pressão exercida pela organização de ensino superior e seu sistema de avaliação, na "compulsão" para se concluir o mestrado e o doutorado em prazos exíguos, no apelo à ascensão rápida na carreira universitária, que leva a um em- pobrecimento da formação intelectual. Há ainda a pressão do sistema para que professores, alunos e instituições de ensino se adéqüem a um padrão quantitativista e produtivista de avaliação, que exige mais e mais números indicativos de produção.

0 sétimo problema refere-se à crítica da dependência dos autores brasil ei ros em relação à literatura estrangeira. A crítica tem razão na medida em que se vê aí uma reprodução extemporânea de uma mentalidade colonial ou colonial ista que só valoriza o estrangeiro e despreza o nacional. Ela também vale para a cópia acrítica ou sem as adaptações necessárias dos modelos de gestão externos, certamente eficazes e eficientes para solucionar problemas administrativos dos países onde e para os quais foram produzidos. Por outro lado, a crítica ao mimetismo deve ser ponderada quando se examina a história do desenvolvimento universal, que é híbrida, feita mais de empréstimos (conforme apregoa Fernand Braudel) e imitações do que de originalidades. Uma maior referência aos autores estrangeiros pelos acadêmicos brasileiros, mais do que uma opção, pode ser considerada como uma contingência, uma virtude e uma necessidade. É uma contingência histórica porque, quer queira ou não, a universidade, o capitalismo e a ciência desenvolveram-se primeiro e com maior intensidade nos chamados países centrais do que nos periféricos e emergentes. A té hoje, as conseqüências do maior desenvolvimento desses três fenômenos nos países centrais não foram revertidas. Esse dado estrutural é um fator permanente a al imentar essa dependência. Ainda, como forma de minimizar essa contingência, pode-se afirmar que citar a literatura estrangeira é uma virtude que significa atualização e atualidade, valores não ape- 
nas cultivados, mas cobrados pela universidade.

O oitavo problema, mesmo sendo abrangente, atinge em cheio a Administração, e está relacionado ao enfrentamento da crise de valores da sociedade. Essa crise atinge as pessoas, os governos, as relações internacionais e os negócios - por exemplo, com a maquiagem dos balanços e os recentes escândalos que abalaram a credibilidade de organizações tidas até então como baluartes da retidão. 0 que a universidade poderá fazer, e mais especificamente a Administração? Além de formar o autor, o pensador, o produtor de conhecimentos e o inovador, ela não pode abrir mão da sua responsabilidade de formar o cidadão e a pessoa humana na sua plenitude. Conforme afirma Edgar Morin, a universidade "conserva, memoriza, integra, ritualiza uma herança cultural de saberes, idéias, valores; regenera essa herança ao reexaminá-la, atualizá-la, transmitila. Gera saberes, idéias e val ores que passam, então, a fazer parte da herança" (A cabeça bem-feita. Rio de Janeiro: Bertrand-Brasil, 2001, p. 81).

Deve-se reafirmar o modelo do homem, da mulher e do cidadão proposto pelo Renascimento e pela Modernidade: um ser autônomo, dono de seu próprio destino, comprometido com o desenvolvimento do seu país, a sobrevivência da humanidade, os direitos humanos, a ética, a democracia e a paz. Os valores do Humanismo e o ideário da Modernidade continuam sendo imprescindíveis para se viver no mundo global. Para aprender a operar com o excesso de informações, para resistir à massificação, ao fundamentalismo e fanatismo, ao terrorismo, às guerras de invasão, aos genocídios e às tiranias.

Por fim, um último problema diz respeito à diversidade do ensino superior brasileiro. A Constituição Federal de 1988 consagra um modelo de universidade que supõe indissolubilidade entre ensino, pesquisa e extensão, autonomia didática, administrativa e de gestão financeira e patrimonial, oferta de cursos de mestrado e doutorado, e realização de pesquisas e estudos avançados.

A realidade do ensino superior brasileiro é bem diferente, porque o sistema é formado por universidades, centros universitários, faculdades isoladas, escolas e institutos de educação superior e centros de educação tecnológica. Como essas diversas instituições convivem entre si? Não parecem conviver amigavel mente, nem de maneira complementar. As universidades públicas tratam com reservas o sistema privado e lutam para manter sua hegemonia sobre o sistema e sua primazia na captação de recursos públicos. A própria diversificação na pós-graduação, com a criação dos mestrados profissionalizantes em administração, tem sido criticada pelas universidades que mantêm mestrados acadêmicos. 0 sistema privado, por sua vez, questiona a hegemonia do sistema público e o controle que este exerce sobre o sistema de regulação do Estado e sobre as agências federais e estaduais de fomento e de financiamento à pesquisa. Como mudar essa situação em benefício do país?

Admitidas a diversidade e complementaridade do sistema, alguns ajustes seriam necessários. 0 próprio sistema de avaliação do ensino de graduação e de pós-graduação precisaria ser adaptado para dar conta da diversidade, reconhecendo a contribuição positiva de cada segmento do ensino para o desenvolvimento do país. A diversidade atende e é funcional às necessidades regionais e de interiorização do ensino. As instituições de ensino superior são, com raras exceções, alternativas de promoção de pessoas e da cultura regional. São oportunidades de ascensão social. Isso impacta naturalmente a lógica dos cursos e programas de administração.

De maneira conclusiva, ao apresentar os diversos problemas, muitas alternativas para suas su perações já foram sugeridas. Isso não dispensa al gumas considerações finais sobre o que precisa ser feito. Por onde crescer? Como superar os limites ou o estágio atual?

De forma resumida, o ensino deve prioritariamente incentivar a reflexão para a criatividade, a inventividade e a inovação. Não deve limitarse a oferecer aos alunos modelos já constituídos, mas estimulá-los a buscar e a testar novos caminhos. Para tanto, deve-se combater a hiperespecialização e o ensino fragmentado, estimulando o conhecimento de obras inteiras e a leitura interessada mais do que a interesseira.

O conhecimento dos clássicos da Administração e das ciências sociais deverá estar sempre presente na formação dos alunos de graduação, mestrado e doutorado, não para repassar lições imortais, mas para exercitar a liberdade frente às limitações e às mudanças do cotidiano. Isso porque a nova realidade e 0 nosso conhecimento sobre ela são sempre provisórios, tanto quanto as leis científicas, que apenas vigoram enquanto não forem refutadas.

Por fim, será necessário lembrar que os próprios paradigmas da ciência estão em mutação. De acordo com Edgar Morin, os quatro princípios ordem, separação, redução e validade absoluta da lógica clássica - que fundamentavam a ciência cartesiana de causalidade linear estão supera- 
dos. 0 primeiro (ordem), derivado do estudo da natureza e do mundo, está sendo revisto porque explica a repetição, mas não dá conta do novo, da criação e da inovação. 0 segundo princípio (separação), diz respeito ao conhecimento objetivo que separa o objeto a ser conhecido do sujeito conhecedor. Ele está na base da especialização das disciplinas e do ensino. Sabe-se, hoje, que as grandes descobertas científicas ocorrem em domínios intermediários ou em zonas incertas e fronteiriças, o que estimula a interdisciplinaridade. 0 terceiro princípio (redução), que permite conhecer o todo pelas partes, não tem mais a mesma validade hoje porque o todo é mais do que a soma das partes. Por fim, está sendo questionado o quarto princípio (validade absoluta) da lógica clássica, que atribui valor de verdade à indução e à dedução porque ele elimina de qualquer modelo analítico a contradição, vista como erro.
Os quatro princípios que fundavam a causalidade linear estão sendo substituídos pelo pensamento da complexidade, que, segundo Edgar M orin, deverá ter quatro características:

\section{[...] ser um pensamento que compreenda que o conhecimen- to das partes depende do conhe- cimento do todo e que o conhe- cimento do todo depende do co- nhecimento das partes; reconhe- ça e examine os fenômenos mul- tidimensionais, em vez de isolar, de maneira mutiladora, cada uma de suas dimensões; reconheça e trate as realidades que são, con- comitantemente solidárias e con- flituosas (como a própria demo- cracia, sistema que se alimenta de antagonismos e ao mesmo tem- po os regula); respeite a diferen- ça, enquanto reconhece a unici- dade. (MORIN, E. A cabeça bem- feita. Rio de Janeiro: Bertrand- Brasil, 2001, p. 88-89).}

E completa afirmando que "é preciso substituir um pensamento que isola e separa por um pensamento que distingue e une. É preciso substituir um pensamento disjuntivo e redutor por um pensamento do complexo, no sentido originário de termo 'complexus': o que é tecido junto" (ibidem). 0 pensamento do complexo trabalha com o princípio da complementaridade para dar conta da relação dialógica entre ordem, desordem e auto-organização, que são noções antagônicas entre si, mas sem eliminar a contradição entre elas, permanecendo irredutíveis e ligadas intimamente. A ciência, ao libertar-se dos paradigmas clássicos e totalizantes, abriu espaço para a revisão, a experimentação, a inovação, a imaginação e a criatividade. Qual será o resultado final desse processo de renovação da ciência e da administração, não se sabe ainda. Sabese, apenas, que ele tem o céu como limite, porque infinda é a capacidade humana.

\title{
Pensata convidada. Aprovada em 07.08.2005.
}

\author{
Domingos Giroletti \\ Professor do M PA/FCHPL e ex-professor da UFMG. Pós-doutorado pela \\ London School of Economics and Political Science (LSE). \\ Interesses de pesquisa nas áreas de gestão, inovação e governança, cultura \\ organizacional e responsabilidade social. \\ E-mail: d.giroletti@terra.com.br \\ Endereço: Rua Ovídio de Andrade, 43/101, Belo Horizonte - M G, 30330-170.
}

